\title{
Experience of laparoscopic liver resection for various liver diseases
}

\author{
Juhong Park, Seokhwan Kim, Insang Song, and Kwangsik Chun
}

\author{
Department of Surgery, Chungnam National University Hospital, Daejeon, Korea
}

\begin{abstract}
Backgrounds/Aims: We present our experience of laparoscopic liver resection for various liver diseases. Methods: From April 2008 to August 2012 in Chungnam National University, 68 of 253 liver resections were performed laparoscopically. During the first year, laparoscopy-assisted liver resection was mainly performed and subsequently totally laparoscopic liver resection was the main operative type. Surgery type for treatment purposes was decided preoperatively. Clinical data were collected retrospectively and analyzed. Results: Preoperatively, 43 patients $(63.2 \%)$ were diagnosed with benign disease, 19 patients (27.9\%) were malignant liver tumors and 6 patients $(8.8 \%)$ were indeterminate liver tumor but favorable towards malignancy. Anatomical major liver resection was performed in 58 cases (85.3\%) and 10 cases $(14.7 \%)$ were non-anatomical resection. Left hemihepatectomy was performed in 38 cases $(55.8 \%)$ followed by left lateral sectionectomy in 18 cases (26.5\%), and segment IV and IVa segmentectomy, were each in 1 case. Mean operation time was 235.0 minutes (range, 60-470) and 14 patients (18.6\%) had intraoperative transfusion. Mean postoperative hospital stay was 10.2 days (range, 4-32). Mean operation time of laparoscopy-assisted left lobectomy was 317 minutes and totally laparoscopic left lobectomy was 281 minutes, but there was no significant statistical difference between these two operation types. There were 11 episodes of postoperative complications in 8 patients. There was no mortality after laparoscopic liver resection. Conclusions: We concluded that laparoscopic liver resection is a feasible operation, but needs to be carefully conducted in malignant tumors. (Korean J Hepatobiliary Pancreat Surg 2014;18:112-117)
\end{abstract}

Key Words: Laparoscopy; Liver resection; Liver tumor

\section{INTRODUCTION}

During the past 2 decades since the first report of laparosopic liver resection, there have been major developments in minimally invasive liver surgical technique, laparoscopic instrumentation, radiologic imaging, intensive anesthetics, and postoperative care. ${ }^{1,2}$ Laparoscopic liver resections are now an attractive method for various liver diseases in many centers. ${ }^{3}$ Moreover, oncological safety indices, such as disease free survival, and overall survival are reportedly comparable to those of open surgery. ${ }^{3-7}$ Technical challenges for mobilization of heavy organ, transection of parenchyma with its potential for significant bleeding, absence of anatomical markers, satisfactory oncologic clearance, and difficulties in localization of deep seated tumor with underlying liver cirrhosis still make laparoscopic liver resection a difficult operation. ${ }^{6,8,10} \mathrm{We}$ present our initial experiences of laparoscopic liver re- section performed for various liver diseases.

\section{MATERIALS AND METHODS}

From April 2008 to August 2012 in Chungnam national university, 68 cases of laparoscopic liver resection were performed among 253 liver resections. Unlooping or marsupialization of hepatic cyst was not included in these patients. During the first year, laparoscopy assisted liver resection was mainly performed and in subsequent years totally laparoscopic liver resection was the main operative type. Clinical data were collected retrospectively.

Type of liver resection for treatment purposes was decided preoperatively. Benign liver diseases, especially intrahepatic duct (IHD) stones with recurrent pyogenic cholangitis (RPC), were considered for laparoscopic liver resection but right sided, complex IHD stones with pyogenic cholangitis were excluded from laparoscopic

Received: October 29, 2014; Revised: November 7, 2014; Accepted: November 16, 2014

Corresponding author: Kwangsik Chun

Department of Surgery, Chungnam National University Hospital, 282, Munhwa-ro, Jung-gu, Daejeon 301-721, Korea Tel: +82-42-280-7185, Fax: +82-42-280-7185, E-mail: oxali@hanmail.net

Copyright (C) 2014 by The Korean Association of Hepato-Biliary-Pancreatic Surgery

This is an Open Access article distributed under the terms of the Creative Commons Attribution Non-Commercial License (http://creativecommons.org/ licenses/by-nc/3.0) which permits unrestricted non-commercial use, distribution, and reproduction in any medium, provided the original work is properly cited. Korean Journal of Hepato-Biliary-Pancreatic Surgery • pISSN: 1738-6349 - eISSN: 2288-9213 
surgery. Benign liver tumors were included for laparoscopic liver resection. Laparoscopic liver resection for malignant liver tumor was considered according to the size of mass, location, and expected number of resections (Figs. 1, 2).

Laparoscopic assisted liver resection was defined as preoperatively decided, open conversion for liver parenchymal dissection. Conversion to open surgery due to any incidental problem such as massive bleeding, and severe adhesion was regarded as open conversion. Totally laparoscopic liver resection was defined as an entire procedure that was performed laparoscopically.

\section{RESULTS}

Mean age was 60.5 years (range, 29-85), male-to-female gender ratio was $1: 1.6$. Preoperatively 43 patients $(63.2 \%)$ were diagnosed with benign diseases, 19 patients $(27.9 \%)$ were malignant liver tumors and 6 patients (8.8\%) were indeterminate liver tumor but favorable to develop malignancy, such as suspicious hepatocellular carcinoma, and metastatic liver tumors. Indeterminate liver tumors were pathologically confirmed as biliary cystadenoma in 3 cases, cavernous hemangioma in 2 cases and focal nodular hyperplasia in 1 case on confirmatory

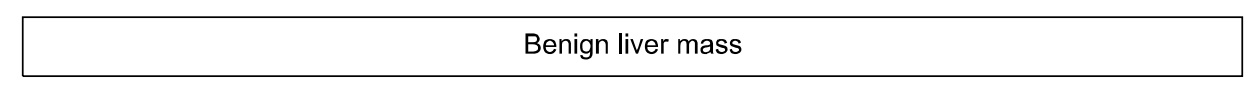

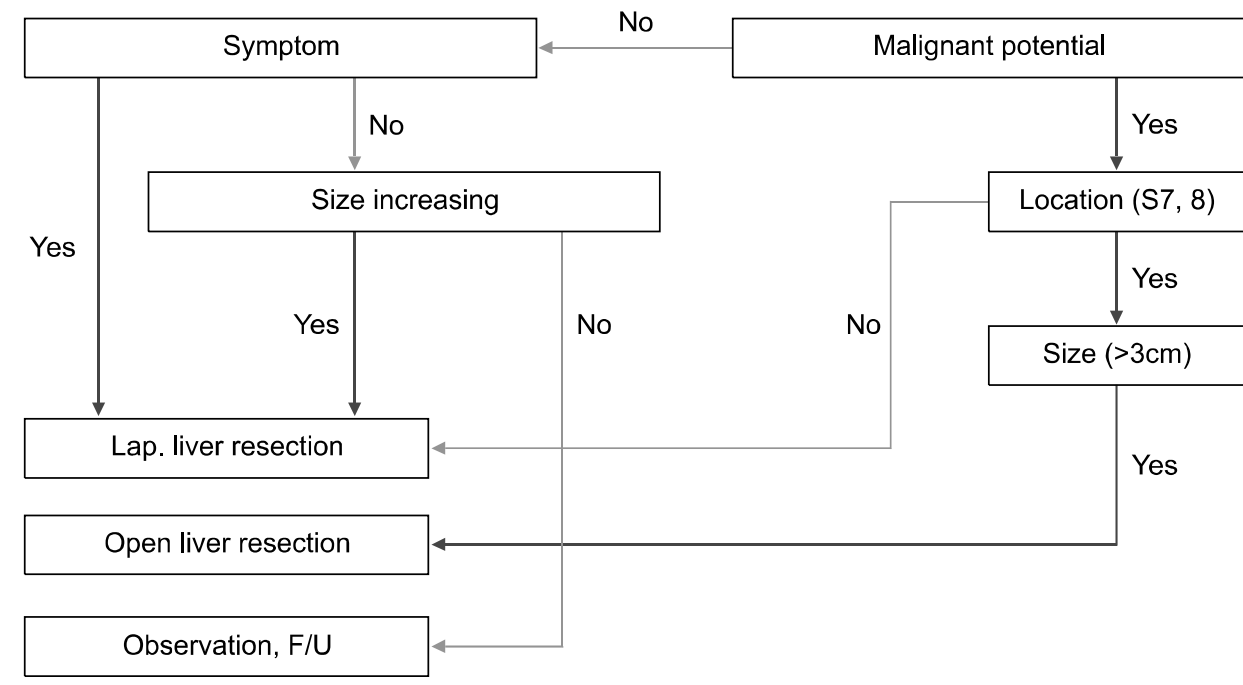

Malignant liver mass

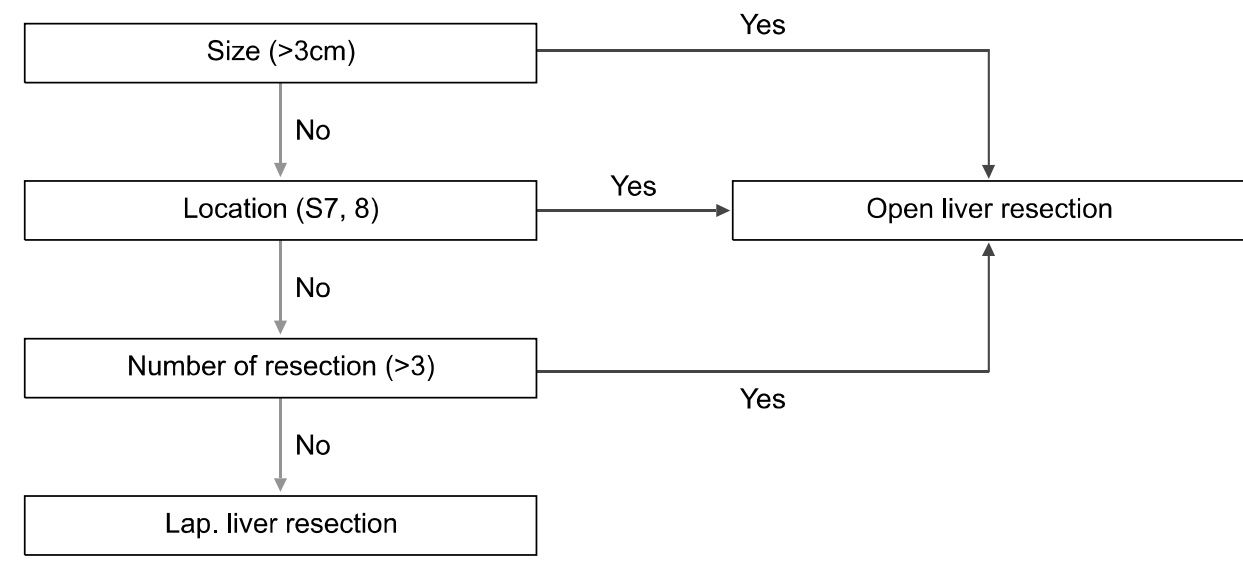

Fig. 1. Indication of laparoscopic liver resection for benign liver mass $(\mathrm{F} / \mathrm{U}=$ follow-up).
Fig. 2. Indication of laparoscopic liver resection for benign liver tumors. 
pathologic diagnosis. Mean American Society of Anesthesiologists (ASA) score was 1.72 (range, 1-4). There were 21 cases with underlying liver diseases. Fatty liver was found in 12 cases. Child-Pugh classification Liver cirrhosis was found in 9 cases (Table 1).

Among benign diseases (50 cases according to pathologic diagnosis, 73.5\%), IHD stone with recurrent pyogenic cholangitis was the most frequent disease $(n=37$, $54.4 \%)$ followed by biliary cystadenoma $(n=4,1.5 \%)$ and hemangioma $(n=4,1.5 \%)$. Among malignant liver tumors (18 cases according to pathologic diagnosis, 26.5\%), hepatocellular carcinoma occurred in 13 cases and metastatic liver cancer from colorectal cancer in 5 cases (Table 1).

Anatomical major liver resection was performed in 58 cases $(85.3 \%)$ and 10 cases $(14.7 \%)$ had non-anatomical resection. Left hemihepatectomy was performed in 38 cases $(55.8 \%)$ followed by left lateral sectionectomy in 18 cases $(26.5 \%)$, and 1 case each had segment IV and IVa segmentectomy, respectively. Laparoscopy-assisted liver resection was performed in 15 cases $(22.1 \%)$ and totally laparoscopic liver resection in 49 cases $(72.1 \%)$. Four cases had open conversion during laparoscopic anatomical liver resection due to bleeding in 2 cases and severe adhesion with anatomical alteration in 2 cases (Table 2).

Mean operation time was 235.0 minutes (range, 60-470) and intraoperative transfusion was done in 11 patients (16.1\%). Mean postoperative hospital stay was 10.2 days (range, 4-32). Mean operation time of laparoscopic assisted left lobectomy was 317.0 minutes and totally laparoscopic left lobectomy was 281.0 minutes $(p>0.05)$.

Table 1. Characteristics of the patients

\begin{tabular}{|c|c|c|}
\hline \multicolumn{3}{|l|}{ Characteristics } \\
\hline Mean age (year) (range) & & $60.5(29-85)$ \\
\hline Gender ratio $(\mathrm{M}: \mathrm{F})$ & & $1: 1.6$ \\
\hline Mean ASA score (mean) & & 1.72 \\
\hline \multicolumn{3}{|l|}{ Pathologic diagnosis $(\mathrm{n}, \%)$} \\
\hline & Malignant disease $(n=18)$ & \\
\hline & Colorectal cancer liver metastasis & $5(7.4)$ \\
\hline & Hepatocellular carcinoma & $13(19.1)$ \\
\hline & \multicolumn{2}{|l|}{ Benign disease $(\mathrm{n}=50)$} \\
\hline & Biliary cystadenoma & $4(5.9)$ \\
\hline & Focal nodular hyperplasia & $2(2.9)$ \\
\hline & Hemangioma & $4(5.9)$ \\
\hline & Intrahepatic duct stone & $37(54.4)$ \\
\hline & Mesenchymal Harmatoma & $1(1.5)$ \\
\hline & Mucinous cystic neoplasm & $1(1.5)$ \\
\hline & Hepatic cyst & $1(1.5)$ \\
\hline \multirow[t]{2}{*}{ Underlying liver disease } & Liver cirrhosis & $9(13.2)$ \\
\hline & Fatty liver & $12(17.6)$ \\
\hline
\end{tabular}

ASA, American Society of Anesthesiologists

Table 2. Operation types

\begin{tabular}{|c|c|c|c|c|}
\hline \multirow[b]{2}{*}{ Operation type } & \multicolumn{2}{|c|}{ Benign disease $(n=50)$} & \multirow{2}{*}{$\begin{array}{l}\text { Malignancy } \\
\quad(n=18)\end{array}$} & \multirow{2}{*}{$\begin{array}{l}\text { Mean operation } \\
\text { time (min) }\end{array}$} \\
\hline & $\begin{array}{c}\text { Intrahepatic } \\
\text { duct stone }(n=37)\end{array}$ & $\begin{array}{c}\text { Benign } \\
\text { tumor }(n=13)\end{array}$ & & \\
\hline Laparoscopy-assisted LLS & 1 & & 2 & 258.3 \\
\hline Laparoscopic LLS & 2 & 3 & 10 & 160.9 \\
\hline Laparoscopy-assisted LL & 10 & & 2 & 317.0 \\
\hline Laparoscopic LL & 21 & 1 & & 281.0 \\
\hline Laparoscopic SIV segmentectomy & & 1 & & 240.0 \\
\hline Laparoscopic SIVa segmentectomy & & 1 & & 124.0 \\
\hline Laparoscopic nonanatomical resection & & 6 & 4 & 133.5 \\
\hline Open conversion & 3 & 1 & & \\
\hline
\end{tabular}

LL, left lobectomy; LLS, left lateral sectionectomy; SIV, segment IV; SIVa, ventral part of the segment IV 
Table 3. Clinical outcomes

\begin{tabular}{|c|c|c|c|}
\hline & Intrahepatic duct stone $(n=37)$ & Benign tumor $(n=13)$ & Malignancy $(n=18)$ \\
\hline Mean operation time (min) & $290.9(165-470)$ & $157.0(60-375)$ & $172.7(60-410)$ \\
\hline Intra operation transfusion (n) & 8 patients & 2 patients & 1 patients \\
\hline Complication & $\begin{array}{l}\text { Postoperative bleeding }(\mathrm{n}=1) \\
\text { Bile leakage }(\mathrm{n}=2) \\
\text { Atelectasis }(\mathrm{n}=1) \\
\text { Pleural effusion }(\mathrm{n}=1) \\
\text { Indigestion }(\mathrm{n}=1) \\
\text { Intraabdominal abscess }(\mathrm{n}=1) \\
\text { Delayed gastric emptying }(\mathrm{n}=1)\end{array}$ & & \\
\hline Mean hospital stay (days, range) & $12.0(5-49)$ & $7.6(3-21)$ & $7.1(4-16)$ \\
\hline \multicolumn{4}{|l|}{ Underlying liver disease } \\
\hline Fatty liver & 3 & 2 & 7 \\
\hline Liver cirrhosis & 1 & 1 & 7 \\
\hline
\end{tabular}

Table 4. Operative results of malignant tumors

\begin{tabular}{lc}
\hline \multicolumn{1}{c}{ Location } \\
\hline Segment II, III & 16 \\
Segment V & 1 \\
Segment VI & 1 \\
Resectionmargin (cm) & 1.76 (range, $0.8-4.5)$ \\
Tumor size (cm) & 2.26 (range, 1.2-5.0) \\
Recurrence (n, \%) & $4(22 \%)$ \\
2-year disease-free survival rate & $69.8 \%$ \\
2-year overall survival rate & $90.9 \%$ \\
\hline
\end{tabular}

Laparoscopy-assisted left lateral sectionectomy was performed in 258.3 minutes, but totally laparoscopic left lateral sectionectomy in 160 minutes (Table 2).

Complications occurred in 8 patients. Transient hyperbilirubinemia and bile leakage occurred in each of 2 cases. Pulmonary atelectasis, indigestion, pleural effusion, intraabdominal abscess and delayed gastric emptying occurred in 1 of each case. These were conservatively managed. However, 1 case of postoperative bleeding required reoperation. There was no mortality after laparoscopic liver resection (Table 3).

Among 18 cases of malignant tumors, sixteen cases are located at left lateral section and two case were at segment V and VI. One case (20\%) of colorectal cancer liver metastasis and 3 cases $(23 \%)$ of hepatocellular carcinoma were recurrent and 1 patient with colorectal cancer liver metastasis expired. Mean resection margin was $1.76 \mathrm{~cm}$ (range, 0.8-4.5), mean tumor size was $2.26 \mathrm{~cm}$ (range, 1.2-5.0) in diameter. The 2-year disease-free survival was $69.8 \%$ and 2-year overall survival was $90.9 \%$ (Table 4 ).

\section{DISCUSSION}

The aim of laparoscopic liver resection is to preserve the advantages of the general laparoscopic procedure, without compromising the principles of open liver surgery. The indication for laparoscopic liver resection should therefore follow the same guidelines of open liver resection. According to the Louiseville statement, patients with solitary lesion, $<5 \mathrm{~cm}$, and within the peripheral segments in malignant tumors may generally be amendable to laparoscopic liver resection, and major hepatectomies are reserved for specialized liver centers. ${ }^{11}$ The indication for laparoscopic liver resection in our study followed these guidelines. ${ }^{11,12}$ Six patients with indeterminate liver tumors were postoperatively confirmed as benign diseases, but these were more favorable towards malignancy according to repeated radiologic studies.

The anatomical location of a tumor is the major concern for the applicability of laparoscopic liver resection. Some centers have reported safe laparoscopic resection of malignant tumor lesions localized to the superior posterior segment, deep seated lesions, or close to the hilum, major hepatic vein or inferior vena cava. ${ }^{8,9,12,13}$ It would be safe to adopt laparoscopic liver resection for some of these lesions, however tumor localization, exposure especially in underlying liver cirrhosis and obtaining a safe resection margin are more difficult. ${ }^{14}$ Most early liver resections were limited to the peripheral or left segment of the liver because of minimal mobilization and less complex dissection. Left lateral section was the most common site of tumor in the enrolled laparoscopic liver resection cases. 
Segment IV and anterior inferior segment of right liver were removed in 7 and 4 cases, respectively. The reason for our result was that individual ligation of the left hepatic artery and portal vein is easier than the right sided and right glissonian approach, and has more ease of mobilization, and easier laparoscopic sonographic localization than that of the right liver.

Laparoscopic liver resection for intrahepatic duct stone differs from that of liver tumors because most intrahepatic duct stones are combined with RPC and anatomical distortions, including parenchymal atrophy, bile duct dilatation with or without proximal stricture and multiplicity of stone locations. All complication in our cases occurred in the IHD stone group despite the low rate of underlying liver disease. Operation time was longer in the IHD group than others. The treatment must include complete removal of stones and resolution of IHD stricture and cholestasis. Various modalities of treatment, including percutaneous transhepatic cholangioscopic lithotripsy and laparoscopic intrahepatic duct exploration were adapted. These modalities are often incomplete, repeated and require combined procedures for complete removal of stones. If ductal strictures and RPC were comorbid with IHD stone, definitive hepatectomy was necessary. In our study over half (37 patients) of laparoscopic liver resection were performed for IHD stones with RPC, and all of these patients had anatomical left liver resection. Combined common bile duct stone or right hepatic duct stone were removed by choledochoscopic stone extraction through the left main duct or new choledochotomy. The main concerns in these procedures were remnant stones and postoperative bile leakage. There was no remnant stone, but 2 cases of bile leakage occurred postoperatively and were treated by conservative management.

Oncological safety is another major concern of laparoscopic and open liver resections for malignant tumors. Results from several multicenter international group studies for colorectal cancer liver metastasis showed that the 5 -year survival rate for laparoscopic liver resection was $50 \%$ to $64 \%$, with $\mathrm{R} 0$ resection rates similar to that of open surgery. ${ }^{6,15-17}$ Cherqui et al. ${ }^{18}$ found that the 3-year survival rate for patients with peripheral hepatocellular carcinoma undergoing laparoscopic liver resection was $93 \%$, with an acceptable $30 \%$ overall recurrence rate. During the follow-up period in our study, 1 case $(20 \%)$ of colorectal cancer liver metastasis and 3 cases $(23 \%)$ of hepatocellular carcinoma were recurrent and 1 patient with colorectal cancer liver metastasis expired. Mean resection margin was $1.76 \mathrm{~cm}$ (range, 0.8-4.5), mean tumor size was $2.26 \mathrm{~cm}$ (range, 1.2-5.0) in diameter. The 2-year disease-free survival was $69.8 \%$ and 2 -year overall survival was $90.9 \%$, but direct comparison to other studies was not meaningful because of the short follow-up period and small number of patients.

Reddy et al. ${ }^{1}$ reviewed worldwide laparoscopic liver resection and showed that intraoperative blood transfusion and postoperative complications were more frequent in open liver resection than laparoscopic liver resection. Cai et al. ${ }^{19}$ reported intraoperative blood loss and higher transfusion rates in the open resection group, but did not show statistical differences; moreover, the postoperative complication and length of stay was not significantly different. We did not attempt a comparative analysis between laparoscopic liver resection and open resection, but focused instead on parenchymal dissection in left hemihepatectomy where there were no significant differences in operation time and intraoperative transfusion rates between the laparoscopic assisted group and totally laparoscopic group. Moreover in our study underlying liver diseases such as liver cirrhosis, fatty liver influenced the transfusion and conversion rates.

The results of our initial series of laparoscopic liver resections indicated that laparoscopic liver resection, especially for the left lobe, is a good candidate treatment that is feasible for benign and malignant tumors in select cases, as well as for tumors located in the periphery of the liver.

\section{REFERENCES}

1. Reddy SK, Tsung A, Geller DA. Laparoscopic liver resection. World J Surg 2011;35:1478-1486.

2. Azagra JS, Goergen M, Gilbart E, Jacobs D. Laparoscopic anatomical (hepatic) left lateral segmentectomy-technical aspects. Surg Endosc 1996;10:758-761.

3. Mostaedi R, Milosevic Z, Han HS, Khatri VP. Laparoscopic liver resection: current role and limitations. World J Gastrointest Oncol 2012;4:187-192.

4. Baker TB, Jay CL, Ladner DP, Preczewski LB, Clark L, Holl $\mathrm{J}$, et al. Laparoscopy-assisted and open living donor right hepatectomy: a comparative study of outcomes. Surgery 2009;146: 817-823.

5. Castaing D, Vibert E, Ricca L, Azoulay D, Adam R, Gayet B. Oncologic results of laparoscopic versus open hepatectomy for 
colorectal liver metastases in two specialized centers. Ann Surg 2009;250:849-855.

6. Bryant R, Laurent A, Tayar C, Cherqui D. Laparoscopic liver resection-understanding its role in current practice: the Henri Mondor Hospital experience. Ann Surg 2009;250:103-111.

7. Chang S, Laurent A, Tayar C, Karoui M, Cherqui D. Laparoscopy as a routine approach for left lateral sectionectomy. Br J Surg 2007;94:58-63.

8. Kurosaki I, Yamamoto S, Kitami C, Yokoyama N, Nakatsuka $\mathrm{H}$, Kobayashi $\mathrm{T}$, et al. Video-assisted living donor hemihepatectomy through a $12-\mathrm{cm}$ incision for adult-to-adult liver transplantation. Surgery 2006;139:695-703.

9. Yoon YS, Han HS, Cho JY, Ahn KS. Total laparoscopic liver resection for hepatocellular carcinoma located in all segments of the liver. Surg Endosc 2010;24:1630-1637.

10. Buell JF, Thomas MT, Rudich S, Marvin M, Nagubandi R, Ravindra KV, et al. Experience with more than 500 minimally invasive hepatic procedures. Ann Surg 2008;248:475-486.

11. Buell JF, Cherqui D, Geller DA, O'Rourke N, Iannitti D, Dagher I, et al; World Consensus Conference on Laparoscopic Surgery. The international position on laparoscopic liver surgery: The Louisville Statement, 2008. Ann Surg 2009;250:825-830.

12. Nguyen KT, Gamblin TC, Geller DA. World review of laparoscopic liver resection-2,804 patients. Ann Surg 2009;250:831-841.
13. Cho JY, Han HS, Yoon YS, Shin SH. Feasibility of laparoscopic liver resection for tumors located in the posterosuperior segments of the liver, with a special reference to overcoming current limitations on tumor location. Surgery 2008;144:32-38.

14. Cho JY, Han HS, Yoon YS, Shin SH. Experiences of laparoscopic liver resection including lesions in the posterosuperior segments of the liver. Surg Endosc 2008;22:2344-2349.

15. Qiu J, Chen S, Pankaj P, Wu H. Laparoscopic hepatectomy for hepatic colorectal metastases: a retrospective comparative cohort analysis and literature review. PLoS One 2013;8:e60153.

16. Sasaki A, Nitta H, Otsuka K, Takahara T, Nishizuka S, Wakabayashi G. Ten-year experience of totally laparoscopic liver resection in a single institution. Br J Surg 2009;96:274-279.

17. Kazaryan AM, Marangos IP, Røsok BI, Rosseland AR, Villanger $\mathrm{O}$, Fosse E, et al. Laparoscopic resection of colorectal liver metastases: surgical and long-term oncologic outcome. Ann Surg 2010;252:1005-1012.

18. Cherqui D, Laurent A, Tayar C, Chang S, Van Nhieu JT, Loriau $\mathrm{J}$, et al. Laparoscopic liver resection for peripheral hepatocellular carcinoma in patients with chronic liver disease: midterm results and perspectives. Ann Surg 2006;243:499-506.

19. Cai XJ, Wang YF, Liang YL, Yu H, Liang X. Laparoscopic left hemihepatectomy: a safety and feasibility study of 19 cases. Surg Endosc 2009;23:2556-2562. 